Sari Pediatri, Vol. 4, No. 2, September 2002: 59 - 62

\title{
Tata Laksana Kejang Demam pada Anak
}

\author{
Melda Deliana
}

Kejang demam adalah bangkitan kejang yang terjadi pada kenaikan suhu tubuh (suhu rektal lebih dari, $38^{\circ} \mathrm{C}$ ) akibat suatu proses ekstra kranial, biasanya terjadi antara umur 3 bulan dan 5 tahun. Setiap kejang kemungkinan dapat menimbulkan epilepsi dan trauma pada otak, sehingga mencemaskan orang tua. Pengobatan dengan antikonvulsan setiap hari yaitu dengan fenobarbital atau asam valproat mengurangi kejadian kejang demam berulang. Obat pencegahan kejang tanpa demam (epilepsi) tidak pernah dilaporkan. Pengobatan intermittent dengan diazepam pada permulaan pada kejang demam pertama memberikan hasil yang lebih baik. Antipiretik bermanfaat, tetapi tidak dapat mencegah kejang demam namun tidak dapat mencegah berulangnya kejang demam.

Kata kunci: kejang, demam, antikonvulsan

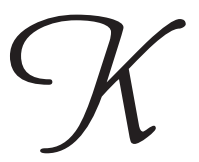

ejang demam adalah bangkitan kejang yang terjadi pada kenaikan suhu tubuh (suhu rektal lebih dari $38^{\circ} \mathrm{C}$ ) akibat suatu proses ekstra kranial. ${ }^{1-4}$ Dalam praktek sehari-hari orang tua sering cemas bila anaknya mengalami kejang, karena setiap kejang kemungkinan dapat menimbulkan epilepsi dan trauma pada otak. ${ }^{5}$ Kejang merupakan gangguan syaraf yang sering dijumpai pada anak. ${ }^{1-3}$ Insiden kejang demam 2,2-5\% pada anak di bawah usia 5 tahun. ${ }^{1-3}$ Anak laki-laki lebih sering dari pada perempuan dengan perbandingan 1,2-1,6:1. ${ }^{1,2}$ Saing B (1999), menemukan $62,2 \%$, kemungkinan kejang demam berulang pada 90 anak yang mengalami kejang demam sebelum usia 12 tahun, dan 45\% pada 100 anak yang mengalami kejang setelah usia 12 tahun. ${ }^{1}$ Kejang demam kompleks dan khususnya kejang demam fokal merupakan prediksi untuk terjadinya epilepsi. ${ }^{6}$ Sebagian besar peneliti melaporkan angka kejadian epilepsi kemudian hari sekitar $2-5 \% .^{3}$

Tujuan tulisan ini adalah mengemukakan adanya pilihan obat lain agar tatalaksana kejang demam menjadi lebih praktis.

\footnotetext{
Alamat Korespondensi:

Dr. Melda Deliana, Sp.A(K).

Bagian Ilmu Kesehatan Anak FK. USU/ RSUP H. Adam Malik Medan. Jl. Bunga Lau No. 17 Medan.

Telepon: 836 0405, 8360143, 836 034. Fax.: 8361721.
}

\section{Diagnosis}

Menurut Consensus Statement on Febrile Seizures, kejang demam adalah bangkitan kejang pada bayi dan anak, biasanya terjadi antara umur 3 bulan dan 5 tahun, berhubungan dengan demam tetapi tidak terbukti adanya infeksi intrakranial atau penyebab lain. ${ }^{7}$

Penggolongan kejang demam menurut kriteria Nationall Collaborative_Perinatal Project adalah kejang demam sederhana dan kejang demam kompleks. Kejang demam sederhana adalah kejang demam yang lama kejangnya kurang dari 15 menit, umum dan tidak berulang pada satu episode demam. Kejang demam kompleks adalah kejang demam yang lebih lama dari 15 menit baik bersifat fokal atau multipel. ${ }^{4}$ Kejang demam berulang adalah kejang demam yang timbul pada lebih dari satu episode demam. ${ }^{3}$ Penggolongan tidak lagi menurut kejang demam sederhana dan epilepsi yang diprovokasi demam tetapi dibagi menjadi pasien yang memerlukan dan tidak memerlukan pengobatan rumat ${ }^{3}$.

Umumnya kejang demam pada anak berlangsung pada permulaan demam akut, berupa serangan kejang klonik umum atau tonik klonik, singkat dan tidak ada tanda-tanda neurologi post iktal, ${ }^{2,3}$

Pemeriksaan EEG pada kejang demam dapat memperlihatkan gelombang lambat di daerah belakang yang bilateral, sering asimetris, kadang-kadang 
unilateral. ${ }^{1,3}$ Pemeriksaan EEG dilakukan pada kejang demam kompleks atau anak yang mempunyai risiko untuk terjadinya epilepsi. ${ }^{8}$

Pemeriksaan pungsi lumbal diindikasikan pada saat pertama sekali timbul kejang demam untuk menyingkirkan adanya proses infeksi intra kranial, ${ }^{7}$ perdarahan subaraknoid atau gangguan demielinasi, ${ }^{8}$ dan dianjurkan pada anak usia kurang dari 2 tahun yang menderita kejang demam. ${ }^{1-3}$

\section{Tata Laksana}

Tujuan pengobatan kejang demam pada anak adalah untuk,

- Mencegah kejang demam berulang

- Mencegah status epilepsi

- Mencegah epilepsi dan / atau mental retardasi

- Normalisasi kehidupan anak dan keluarga.

\section{Pengobatan Fase Akut}

Anak yang sedang mengalami kejang, prioritas utama adalah menjaga agar jalan nafas tetap terbuka. Pakaian dilonggarkan, posisi anak dimiringkan untuk mencegah aspirasi. Sebagian besar kasus kejang berhenti sendiri, tetapi dapat juga berlangsung terus atau berulang. Pengisapan lendir dan pemberian oksigen harus dilakukan teratur, kalau perlu dilakukan intubasi. ${ }^{2,3,9}$ Keadaan dan kebutuhan cairan, kalori dan elektrolit harus diperhatikan. Suhu tubuh dapat diturunkan dengan kompres air hangat (diseka) dan pemberian antipiretik ${ }^{2,3,9,10}$ (asetaminofen oral $10 \mathrm{mg}$ / $\mathrm{kg} \mathrm{BB}, 4$ kali sehari atau ibuprofen oral $20 \mathrm{mg} / \mathrm{kg} \mathrm{BB}$, 4 kali sehari). ${ }^{11}$

Saat ini diazepam merupakan obat pilihan utama untuk kejang demam fase akut, karena diazepam mempunyai masa kerja yang singkat. ${ }^{12}$ Diazepam dapat diberikan secara intravena atau rektal, ${ }^{2,3}$ jika diberikan intramuskular absorbsinya lambat. ${ }^{13}$ Dosis diazepam pada anak adalah $0,3 \mathrm{mg} / \mathrm{kg} \mathrm{BB}$, diberikan secara intravena pada kejang demam fase akut, ${ }^{14}$ tetapi pemberian tersebut sering gagal pada anak yang lebih kecil. ${ }^{15}$ Jika jalur intravena belum terpasang, diazepam dapat diberikan per rektal dengan dosis $5 \mathrm{mg}$ bila berat badan kurang dari $10 \mathrm{~kg}$ dan $10 \mathrm{mg}$ pada berat badan lebih dari $10 \mathrm{~kg} \cdot{ }^{2,3,16}$ Pemberian diazepam secara rektal aman dan efektif serta dapat pula diberikan oleh orang tua di rumah. ${ }^{2,3,9,15}$ Bila diazepam tidak tersedia, dapat diberikan luminal suntikan intramuskular dengan dosis awal $30 \mathrm{mg}$ untuk neonatus, $50 \mathrm{mg}$ untuk usia 1 bulan -1 tahun, dan $75 \mathrm{mg}$ untuk usia lebih dari 1 tahun. ${ }^{2}$ Midazolam intranasal $(0,2 \mathrm{mg} / \mathrm{kg} \mathrm{BB})$ telah diteliti aman dan efektif untuk mengantisipasi kejang demam akut pada anak. ${ }^{12}$ Kecepatan absorbsi midazolam ke aliran darah vena dan efeknya pada sistem syaraf pusat cukup baik; ${ }^{17}$ Namun efek terapinya masih kurang bila dibandingkan dengan diazepam intravena. ${ }^{18}$

\section{Mencari dan Mengobati Penyebab}

Kejang dengan suhu badan yang tinggi dapat terjadi karena faktor lain, seperti meningitis atau ensefalitis. Oleh sebab itu pemeriksaan cairan serebrospinal diindikasikan pada anak pasien kejang demam berusia kurang dari 2 tahun, karena gejala rangsang selaput otak lebih sulit ditemukan pada kelompok umur tersebut. Pada saat melakukan pungsi lumbal harus diperhatikan pula kontra indikasinya. ${ }^{1-3}$ Pemeriksaan laboratorium lain dilakukan atas indikasi untuk mencari penyebab, seperti pemeriksaan darah rutin, kadar gula darah dan elektrolit. Pemeriksaan CT-Scan dilakukan pada anak dengan kejang yang tidak diprovokasi oleh demam dan pertama kali terjadi, terutama jika kejang atau pemeriksaan post iktal menunjukkan abnormalitas fokal. ${ }^{19}$

\section{Pengobatan Profilaksis Terhadap Kejang Demam Berulang}

Pencegahan kejang demam berulang perlu dilakukan, karena menakutkan keluarga dan bila berlangsung terus dapat menyebabkan kerusakan otak yang menetap. ${ }^{2}$

Terdapat 2 cara profilaksis, yaitu, ${ }^{2,3,9}$

- Profilaksis intermittent pada waktu demam

- Profilaksis terus menerus dengan antikonvulsan tiap hari.

\section{Profilaksis Intermittent pada Waktu Demam}

Pengobatan profilaksis intermittent dengan anti konvulsan segera diberikan pada waktu pasien demam 
(suhu rektal lebih dari $38^{\circ} \mathrm{C}$ ). Pilihan obat harus dapat cepat masuk dan bekerja ke otak. ${ }^{2,3}$ Antipiretik saja dan fenobarbital tidak mencegah timbulnya kejang berulang. ${ }^{2,10}$ Rosman $\mathrm{dkk},{ }^{20}$ meneliti bahwa diazepam oral efektif untuk mencegah kejang demam berulang dan bila diberikan intermittent hasilnya lebih baik karena penyerapannya lebih cepat. ${ }^{2,3}$ Diazepam diberikan melalui oral atau rektal.,3,9 Dosis per rektal tiap 8 jam adalah $5 \mathrm{mg}$ untuk pasien dengan berat badan kurang dari $10 \mathrm{~kg}$ dan $10 \mathrm{mg}$ untuk pasien dengan berat badan lebih dari $10 \mathrm{~kg}$. Dosis oral diberikan $0,5 \mathrm{mg} / \mathrm{kg} \mathrm{BB}$ perhari dibagi dalam 3 dosis, diberikan bila pasien menunjukkan suhu $38,5^{\circ} \mathrm{C}$ atau lebih. ${ }^{2,3}$ Efek samping diazepam adalah ataksia, mengantuk dan hipotoni. ${ }^{3}$

Martinez dkk, dikutip dari Soetomenggolo $\mathrm{dkk}^{3}$ menggunakan klonazepam sebagai obat anti konvulsan intermittent $(0,03 \mathrm{mg} / \mathrm{kg} \mathrm{BB}$ per dosis tiap 8 jam) selama suhu diatas $38^{\circ} \mathrm{C}$ dan dilanjutkan jika masih demam. Ternyata kejang demam berulang terjadi hanya pada 2,5\% dari 100 anak yang diteliti. Efek samping klonazepam yaitu mengantuk, mudah tersinggung, gangguan tingkah laku, depresi, dan salivasi berlebihan. ${ }^{3}$

Tachibana dkk, dikutip dari Soetomenggolo dkk ${ }^{3}$ meneliti khasiat kloralhidrat supositoria untuk mencegah kejang demam berulang. Dosis yang diberikan adalah $250 \mathrm{mg}$ untuk berat badan kurang dari $15 \mathrm{~kg}$, dan $500 \mathrm{mg}$ untuk berat badan lebih dari $15 \mathrm{~kg}$, diberikan bila suhu diatas $38^{\circ} \mathrm{C}$. Hasil yang didapat adalah terjadinya kejang demam berulang pada $6,9 \%$ pasien yang menggunakan supositoria kloralhidrat dibanding dengan $32 \%$ pasien yang tidak menggunakannya. Kloralhidrat dikontraindikasikan pada pasien dengan kerusakan ginjal, hepar, penyakit jantung, dan gastritis. ${ }^{8}$

\section{Profilaksis Terus Menerus dengan Antikonvulsan Tiap Hari}

Indikasi pemberian profilaksis terus menerus pada saat ini adalah: ${ }^{2,3}$

- Sebelum kejang demam yang pertama sudah ada kelainan atau gangguan perkembangan neurologis.

- Terdapat riwayat kejang tanpa demam yang bersifat genetik pada orang tua atau saudara kandung.

- Kejang demam lebih lama dari 15 menit, fokal atau diikuti kelainan neurologis sementara atau menetap.

- Kejang demam terjadi pada bayi berumur kurang dari 12 bulan atau terjadi kejang multipel dalam satu episode demam.

Antikonvulsan profilaksis terus menerus diberikan selama $1-2$ tahun setelah kejang terakhir, kemudian dihentikan secara bertahap selama $1-2$ bulan., ${ }^{2,3,21}$ Pemberian profilaksis terus menerus hanya berguna untuk mencegah berulangnya kejang demam berat, tetapi tidak dapat mencegah timbulnya epilepsi di kemudian hari ${ }^{3}$.

Pemberian fenobarbital $4-5 \mathrm{mg} / \mathrm{kg}$ BB perhari dengan kadar sebesar $16 \mathrm{mg} / \mathrm{mL}$ dalam darah menunjukkan hasil yang bermakna untuk mencegah berulangnya kejang demam. ${ }^{1,3}$ Efek samping fenobarbital ialah iritabel, hiperaktif, pemarah dan agresif ditemukan pada 30-50\% kasus. Efek samping fenobarbital dapat dikurangi dengan menurunkan dosis. ${ }^{3}$ Obat lain yang dapat digunakan adalah asam valproat yang memiliki khasiat sama dibandingkan dengan fenobarbital ${ }^{3,22}$. Ngwane meneliti kejadian kejang berulang sebesar 5,5\% pada kelompok yang diobati dengan asam valproat dan $33 \%$ pada kelompok tanpa pengobatan dengan asam valproat. ${ }^{22}$ Dosis asam valproat adalah 15 $40 \mathrm{mg} / \mathrm{kg}$ BB perhari. ${ }^{3}$ Efek samping yang ditemukan adalah hepatotoksik, tremor dan alopesia $^{8,23}$. Fenitoin dan karbamazepin tidak memiliki efek profilaksis terus menerus ${ }^{2,3}$,

Millichap, ${ }^{24}$ merekomendasikan beberapa hal dalam upaya mencegah dan menghadapi kejang demam.

- Orang tua atau pengasuh anak harus diberi cukup informasi mengenai penanganan demam dan kejang.

- Profilaksis intermittent dilakukan dengan memberikan diazepam dosis $0,5 \mathrm{mg} / \mathrm{kg} \mathrm{BB}$ perhari, per oral pada saat anak menderita demam. Sebagai alternatif dapat diberikan profilaksis terus menerus dengan fenobarbital.

- Memberikan diazepam per rektal bila terjadi kejang.

- Pemberian fenobarbital profilaksis dilakukan atas indikasi, pemberian sebaiknya dibatasi sampai 6 - 12 bulan kejang tidak berulang lagi dan kadar fenoborbital dalam darah dipantau tiap 6 minggu -3 bulan, juga dipantau keadaan tingkah laku dan psikologis anak. 


\section{Kesimpulan}

Penatalaksanaan kejang demam pada anak mencakup dalam tiga hal.

1. Pengobatan fase akut yaitu membebaskan jalan nafas dan memantau fungsi vital tubuh. Saat ini diazepam intravena atau rektal merupakan obat pilihan utama, oleh karena mempunyai masa kerja yang singkat. Jika tidak ada diazepam, dapat digunakan luminal suntikan intramuskular ataupun yang lebih praktis midazolam intranasal.

2. Mencari dan mengobati penyebab dengan melakukan pemeriksaan pungsi lumbal pada saat pertama sekali kejang demam. Fungsi lumbal juga dianjurkan pada anak usia kurang dari 2 tahun karena gejala neurologis sulit ditemukan. Pemeriksaan laboratorium penunjang lain dilakukan sesuai indikasi.

3. Pengobatan profilaksis.

a. Intermittent : anti konvulsan segera diberikan pada waktu pasien demam (suhu rektal lebih dari $38^{\circ} \mathrm{C}$ ) dengan menggunakan diazepam oral / rektal, klonazepam atau kloralhidrat supositoria.

b. Terus menerus, dengan memberikan fenobarbital atau asam valproat tiap hari untuk mencegah berulangnya kejang demam.

Pemberian obat-obatan untuk penatalaksanaan kejang demam pada anak, harus dipertimbangkan antara khasiat tarapeutik obat dan efek sampingnya.

\section{Daftar Pustaka}

1. Saing B. Faktor pada kejang demam pertama yang berhubungan dengan terjadinya kejang demam berulang (Studi selama 5 tahun). Medan: Balai Penerbit FK-USU, 1999:1-44.

2. Lumbantobing SM. Kejang demam. Jakarta: Balai Penerbit FK-UI, 1995;1-52.

3. Soetomenggolo TS. Kejang demam. Dalam: Soetomenggolo TS, Ismael S, Panyunting. Neurologi anak. Jakarta: Balai Penerbit IDAI, 1999. h. 244-52.

4. Chistopher M, Verity, Rosemary G, Jean G. Longterm intelectual and behavioral out comes of children with febrile convulsion. N Engl J Med 1998; 388:1723-8.

5. Baumann RJ. Technical report: treatment of the child with simple febrile seizures. Pediatrics 1999; 103:79-86.

6. Verity CM, Golding J. Risk of epilepsy after febrile convulsion: a national cohort study. Br Med J 1991; 303: 1373-6.
7. A Consensus development conference on febrile seizures. Febrile saizures: long term management of children with fever associated seizures. Padiatrics 1980; 66:1009-12.

8. Haslam RHA. The nervous system. Dalam: Behrman RE, Kliegman RM, Arvin AM, Penyunting. Nelson textbook of pediatrics ; edisi ke-15. Philadelphia: Saunders, 1996. h. 1691-5.

9. Nelson KB. Febrile seizures. Dalam: Dodson WE, Pellock JM, Penyunting. Pediatric epilepsy: diagnosis and therapy. New York: Demos, 1993. h. 129-33.

10. Menkes JH, Till K. Paroxysmal disorders. Dalam : Pine JW, Mullen ML, Adin RH, Penyunting. Textbook of child neurology; edisi ke-5. Baltimore: Williams \& Wilkins, 1995. h. 725-814.

11. Melntyre J, Hull D. Comparing efficacy and tolerability of ibuprofen and paracetamol in fever. Arch Dis Child 1996; 74:164-7.

12. Lahat E, Goldman M, Barr J, Eshel G, Berkovitch M. Intranasal midazolam for childhood seizures. Lancet 1998; 352:620-3.

13. Chamberlain JM, Altieri MA, Futterman C, Young GM, Ochsenchlager DW, Waisman Y. A Prospective, randomized study comparing intramuscular midazolam with intravenous diazepam for the treatment of seizures in children. Pediatr Emerg Care 1997; 13:92-4.

14. Committee onquality improvement, Subcommittee on febrile seizures, American Academy of Pediatrics. Practice parameter : long term treatment of the child with simple febrile seizures. Pediatric 1999; 103:1307-9.

15. Knudsen FU. Progress in epilepsy research. Febrile Seizures: treatment and prognosis. Epilepsia 2000; 41:2-9.

16. Dreifuss FE, Rosman NP, Cloyd JC, dkk. A Comparison of rectal diazepam gel and placebo for acute repetitive seizures. N Engl J Med 1998 ; 338:1869-75.

17. Scott RC, Besag FMC, Neville BGR. Buccal midazolam and rectal diazepam for treatment of prolonged seizures in childhood and adolescence: a randomized trial. Lancet 1999; 353:623-6.

18. Berkovitch M. Comparison of intranasal midazolam with intravenous diazepam for treating febrile seizures in children: prospective randomized study. $\mathrm{Br}$ Med J 2000; 321:83-6.

19. Garvey MA, Gailland WD, Rusin JA, dkk. Emergency brain computed tomography in children with seizures: who is most likely to benefit ? J Pediatr 1998; 133:664-9.

20. Rosman NP, dkk. A controlled trial of diazepam administered during febrile illnesses to prevent recurrence of febrile seizures. N Engl J Med 1993; 329:79-84

21. Greenwood RS, Tennison M. When to start and stop anticonvulsant therapy in children. Arch Neural 1999; 56:1073-7.

22. Ngwane E, Bower B. Continous sodium valproate or phenobarbitone in the prevention of simple febrile convulsion. Arch Dis Child 1980; 55:171-4.

23. Samuel L. Pengobatan epilepsi. Dalam: Soetomenggolo TS, Ismael S, Penyunting. Buku Ajar Neurologi Anak. Jakarta : IDAI, 1999. h. 226-43.

24. Millichap JG. Progress in pediatric neurology II, Chaniago: PNB, 1994; 16-9. 